\title{
Polyadenylation and decay of 26S rRNA as part of Nicotiana tabacum response to cadmium ${ }^{\star}$ 光
}

\author{
Małgorzata Lewandowska, Barbara Borcz, Jolanta Kamińska, Adam Wawrzyński \\ and Agnieszka Sirko ${ }^{\bowtie}$
}

Institute of Biochemistry and Biophysics, Polish Academy of Sciences, Warszawa, Poland

Received: 25 July, 2007; revised: 17 September, 2007; accepted: 28 September, 2007

available on-line: 08 December, 2007

\begin{abstract}
In contrast to mRNAs, ribosomal RNAs are generally not considered to be polyadenylated. Only a few recent reports describe non-abundant polyadenylated rRNA-related transcripts that have been detected and characterized in yeast and in human cells. Here we depict the phenomenon of $26 S$ rRNA polyadenylation and degradation that was observed in shoots of Nicotiana tabaccum plants grown in the presence of cadmium. Fragments corresponding to 26S rRNA were identified using suppression subtractive hybridization during screening for genes induced in tobacco plants upon a three-week exposure to $15 \mu \mathrm{M}$ cadmium chloride. Extracts prepared from the aboveground tissues of cadmium-treated tobacco plants were supposed to contain exclusively polyadenylated mRNAs. Surprisingly, numerous polyadenylated fragments matching parts of 26S rRNA were identified and their presence was confirmed by Northern blot and cDNA amplification techniques. To our knowledge this is the first report on rRNA polyadenylation in plants.
\end{abstract}

Keywords: cadmium, programmed cell death, polyadenylation of rRNA, RNA decay, tobacco

\section{INTRODUCTION}

Cadmium $(\mathrm{Cd})$ is a non-essential element, toxic for plants and animals. It influences a variety of plant processes, mainly by oxidative stress. Visible symptoms of $\mathrm{Cd}$ toxicity in plants depend on both time of exposure and metal concentration, and usually include chlorosis of leaves, growth inhibition, browning of root tips and an overall damage of roots. Various aspects of $\mathrm{Cd}$ toxicity in plants have been recently thoroughly reviewed (Benavides et al., 2005; Deckert, 2005). Diverse changes in plant metabolism, such as inhibition of photosynthesis, respiration and nitrogen metabolism as well as decreased water and mineral uptake are observed upon plant exposure to this toxic metal. The defense of plants against $\mathrm{Cd}$ include activation of sulfate assimilation and glutathione biosynthesis (Mendoza-Cozatl et al., 2005; Ortega-Villasante et al., 2005; Mendoza-Cozatl \& Moreno-Sanchez, 2006), synthesis of phytochelatins and compartmentalization of Cd-phytochelatin complexes (Clemens et al., 2001; 2002; Tong et al., 2004), synthesis of other stress-related compounds, for example heat-shock proteins, proline and ethylene (Sanita di Toppi \& Gabbrielli, 1999; Sharma \& Dietz, 2006).

Chronic exposure of plant cells to low concentrations of $\mathrm{Cd}$ or short exposure to high concentrations of $\mathrm{Cd}$ can trigger cell death (Fojtova \& Kovarik, 2000; Yakimova et al., 2006). Programmed

\footnotetext{
$\star^{\star}$ This paper is dedicated to Professor Tadeusz Chojnacki from the Institute of Biochemistry and Biophysics, Polish Academy of Sciences in Warsaw on the occasion of the 50th anniversary of his scientific activity and 75th birthday.

${ }^{\square}$ Author for correspondence: Agnieszka Sirko; Institute of Biochemistry and Biophysics, Polish Academy of Sciences, A. Pawińskiego 5A, 02-106 Warszawa, Poland; e-mail: asirko@ibb.waw.pl

Accession numbers of the nucleotide sequences reported in this work: EU029649 (CD40); EU029653 (CD43), EU029650, EU029651 (fragments obtained after 3'-RACE of CD40); EU029654-EU029659 (fragments obtained after 3'-RACE of CD43).

Abbreviations: EF1a, elongation factor $1 \alpha$; PCD, programmed cell death; real-time RT-PCR, quantitative real-time reverse transcription PCR; RACE, rapid amplification of cDNA ends; SSH, suppression subtractive hybridization.
} 
cell death (PCD) is a process occurring in plants during development and as a response to environmental stresses (Lam et al., 1999; van Doorn \& Woltering, 2005). In animals and plants the PCD-related changes can be monitored by DNA laddering that is traditionally taken as a molecular marker of PCD (Fojtova \& Kovarik, 2000; Pulido \& Parrish, 2003). In animals, during apoptosis, apart from the DNA degradation, also cleavage of $28 \mathrm{~S}$ rRNA (Houge et al., 1993; 1995), $18 \mathrm{~S}$ rRNA (Lafarga et al., 1997) as well as 16S mitochondrial rRNA occurs (Crawford et al., 1997). In eukaryotes, polyadenylation usually stabilizes mRNA, although in bacteria, archaea and organelles polyadenylation is mainly related to RNA decay (Dreyfus \& Regnier, 2002). Recent studies with human cells have shown the occurrence of apoptosis-related polyadenylation-stimulated rRNA degradation (Slomovic et al., 2006). The process of polyadenylation of rRNAs was also observed in the fungal pathogen Candida albicans (Fleischmann \& Liu, 2001) and in Saccharomyces cerevisiae (Kuai et al., 2004). In S. cerevisiae strains lacking the degradation function of Rrp6p - a component of nuclear exosome - the amount of polyadenylated rRNAs increased up to 100-fold in comparison to the wild type strain. In plants, specific cleavage of rRNA and mRNA of some housekeeping genes during victorin-induced apoptotic cell death has recently been reported (Hoat et al., 2006).

In this paper we report that the process of rRNA degradation and polyadenylation occurs in shoots of tobacco plants grown for 3 weeks in the presence of $15 \mu \mathrm{M} \mathrm{CdCl}_{2}$.

\section{MATERIALS AND METHODS}

Plant material and growth conditions. Surface-sterilized seeds of Nicotiana tabacum LA Burley 21 (Legg et al., 1970) were germinated on MS (Murashige \& Skoog, 1962) plates containing 0.8\% agar. Three-week-old plantlets were transferred to liquid $\mathrm{AB}$ medium $\left(3.5 \mathrm{mM} \mathrm{KNO}{ }_{3}, 5 \mathrm{mM} \mathrm{Ca}\left(\mathrm{NO}_{3}\right)_{2}\right.$, $1.7 \mathrm{mM} \mathrm{Mg}\left(\mathrm{NO}_{3}\right)_{2}, 10 \mathrm{mM} \mathrm{NH}_{4} \mathrm{NO}_{3}, 1 \mathrm{mM} \mathrm{KH} \mathrm{PO}_{4}$ $1 \mathrm{mM} \mathrm{MgSO}_{4}, 0.9 \mathrm{mM} \mathrm{MgCl}_{2}, 2 \mathrm{mM} \mathrm{CaCl}, 0.1 \mathrm{mM}$ $\mathrm{NaCl}, 50 \mu \mathrm{M}$ FeNaEDTA, $0.64 \mu \mathrm{M} \mathrm{Cu}\left(\mathrm{NO}_{3}\right)_{2}, 10$ $\mu \mathrm{M} \mathrm{Mn}\left(\mathrm{NO}_{3}\right)_{2}, 0.82 \mu \mathrm{M}\left(\mathrm{NH}_{4}\right)_{2} \mathrm{Mo}_{4} \mathrm{O}_{13}, 0.096 \mu \mathrm{M}$ $\left.\left(\mathrm{CH}_{3} \mathrm{COO}\right)_{2} \mathrm{Zn}, 0.11 \mu \mathrm{M} \mathrm{CoCl}{ }_{2}, 50 \mu \mathrm{M} \mathrm{H}_{3} \mathrm{BO}_{4}\right)$, buffered with $1 \mathrm{mM}$ MES to $\mathrm{pH} 5.8$, and cultivated hydroponically in a growth chamber $\left(16 \mathrm{~h} \mathrm{light,} 20^{\circ} \mathrm{C} / 8\right.$ $\mathrm{h}$ darkness, $\left.18^{\circ} \mathrm{C}\right)$ for about two months. Twomonth-old plants were divided into two groups (every group contained four to six plants): plants grown in the presence of $15 \mu \mathrm{M} \mathrm{CdCl}$ for three weeks and plants from a control group grown without $\mathrm{Cd}$ also for three weeks. Every week the plants were transferred to fresh medium. After three weeks the plants were harvested and divided into roots and shoots. These parts were weighed separately and then pooled. At the end each group (Cd-treated and control) consisted, in total, from over 20 individual plants because plant material from four independent cultivations was pooled.

RNA preparation. Total RNA isolation was performed using TRIZOL Reagent (Invitrogen) according to the procedure recommended by the manufacturer. Subsequently, the poly(A)-containing fraction was purified using Oligotex ${ }^{\circledR}$ mRNA Midi Kit (Qiagen).

Suppression subtractive hybridization (SSH). SSH was carried out using the PCR-Select Subtractive Hybridization Kit (Clontech Laboratories Inc.). Experimental and control samples were processed simultaneously for each treatment to reduce false positives. The amount of poly(A)-containing fraction of RNA was increased to 3-4 $\mu \mathrm{g}$ instead of the $2 \mu \mathrm{g}$ recommended by the manufacturer to compensate for the loss of mRNA during the phenol chloroform extractions. Fragments of cDNA prepared from the Cd-treated samples were used as a "tester" and that from the control samples as a "driver" for the forward subtraction to isolate fragments corresponding to genes whose expression level was increased following the treatment. The reverse subtraction was carried out with the control sample as "tester" to isolate fragments corresponding to genes whose expression level decreased following the treatment. A 500-bp fragment from exon 3 of the Tac9 gene encoding N. tabacum actin (GenBank accession no. X69885) was amplified with ACT1 and ACT2 primers (see Table 1) using the adaptor-ligated cDNA as a template in order to test the efficiency of ligation. Two rounds of PCR amplification were performed in low stringency conditions according to the manufacturer's protocol in order to enrich the pool of differentially regulated genes.

Cloning and differential screening. PCR products, cloned into the T/A cloning vector pGEM-T Easy (Promega) according to manufacturer's instructions, were introduced into $\mathrm{DH} 5 \alpha$ Escherichia coli cells. About 750 colonies from the library containing fragments of genes induced by $\mathrm{Cd}$, and about 550 colonies from the library containing fragments of genes repressed by $\mathrm{Cd}$ were obtained. Randomly picked single colonies were grown $\mathrm{O} / \mathrm{N}$ in $5 \mathrm{ml}$ of liquid $\mathrm{LB}$ medium with $100 \mathrm{mg} \mathrm{l}^{-1}$ ampicillin. Plasmid DNA isolated from these cultures was spotted after heat denaturation $\left(5 \mathrm{~min}, 95^{\circ} \mathrm{C}\right.$ ) in duplicates onto nylon membranes. The membranes were hybridized under stringent conditions with equivalent amounts of labeled probes generated from both subtraction libraries, respectively. DNA probes were non-radioactively 
Table 1. Oligonucleotides used in this study

\begin{tabular}{|c|c|c|}
\hline Name & Sequence $\left(5^{\prime}-3^{\prime}\right)$ & Purpose/Experiment \\
\hline ACT1 & ССТСССАСАTGСTATTСТСС & $\mathrm{SSH}$ - control gene \\
\hline $\mathrm{ACT} 2$ & AGAGCCTCCAATCCAGACAC & $\mathrm{SSH}$ - control gene \\
\hline EF1a-F & GCTCCCACTTCAGGATGTGTA & ${ }^{*}$ rtRT-PCR - control gene \\
\hline EF1a-R & ACACGACCAACAGGGACAGT & rtRT-PCR - control gene \\
\hline RT-CD40F & GCCAAACTCCССАCCTGACAATG & $\begin{array}{l}\text { rtRT-PCR (Fig. 6), } \\
\text { RT-PCR (Fig. 4) }\end{array}$ \\
\hline RT-CD40R & GCCGAAAGGCGAAAGTGAAATACC & rtRT-PCR (Fig. 6) \\
\hline RT-CD43F & AGAGCCGACATCGAAGGATC & rtRT-PCR (Fig. 6) \\
\hline RT-CD43R & GTGAAAGCGTGGCCTAACGA & rtRT-PCR (Fig. 6) \\
\hline RT-26SrRNA3F & AGTTGATTCGGCAGGTGAGTTGT & rtRT-PCR (Fig. 6) \\
\hline RT-26SrRNA3R & TAGGACGGTGCGGCTGCTTT & rtRT-PCR (Fig. 6) \\
\hline TBPnh26SrRNAF & GGAAGAACTTTGCTGGGTGA & RT-PCR (Fig. 4) \\
\hline TBPnh26SrRNAR & TGCCAAATGCTCTGCTGGAA & RT-PCR (Fig. 4) \\
\hline TBPh26SrRNAR & GAACAATGTA GGCAAGGGAAGT & RT-PCR (Fig. 4) \\
\hline 3RACD43Gsp1 & AGCTCACGTTCCCTATTGGTGGGTGAA & 3'-RACE of CD43 \\
\hline 3RACD43Gsp2 & TGATAGGAAGAGCCGACATCGAAGGATC & 3'-RACE of CD43 \\
\hline 3RACD40Gsp1 & AGTCATAGTTACTCCCGCCGTTTACCCGG & 3'-RACE of CD40 \\
\hline 3RACD40Gsp2 & CAGAGCACTGGGCAGAAATCACATTGC & 3'-RACE of CD40 \\
\hline
\end{tabular}

*rtRT-PCR, real-time reverse-ranscription PCR

labeled using PCR digoxygenin-(DIG) Probe Synthesis Kit (Roche Applied Science), while the reaction conditions and the primers were exactly as recommended for the secondary PCR in an SSH experiment with primary PCR products as a template. The DIG-labeled PCR products were applied directly for hybridization without purification. Blots were hybridized and washed according to standard procedures (Sambrook et al., 1989). An immunological detection was carried out using anti-DIG antibodies, conjugated with alkaline phosphatase using DIG Detection Kit (Boehringer Mannheim) following the manufacturer's protocol. A chemiluminescent substrate (CDP-Star Readyto-use, Roche Applied Science) was used for signal development. Membranes were exposed to an X-ray film (X-Omat AR, Kodak) for 1-10 min depending on the strength of the chemiluminescent signals.

Northern-blot analysis. The poly(A)-containing fraction of RNA was separated on a 1\% RNA agarose gel (Sambrook et al., 1989) and transferred to Hybond-N nylon membrane (Amersham Biosciences). RNA immobilized on nylon membranes was visualized by staining in $0.02 \%$ Methylene Blue (Herrin \& Schmidt, 1988) and photographed prior to hybridization.
DNA probes specific to the identified cDNA clones were non-radioactively labeled using PCR digoxygenin-(DIG) Probe Synthesis Kit (Roche Applied Science) and the respective primers (Table 1). Hybridization and detection was as during differential screening (see above).

5'-RACE, 3'-RACE, PCR and RT-PCR. 5'RACE and 3'-RACE libraries were constructed using the SMART ${ }^{\mathrm{TM}}$ RACE cDNA Amplification Kit (BD Biosciences Europe) according to the procedure recommended by the manufacturer and the primers listed in Table 1.

For cDNA synthesis and subsequent PCR that were conducted as previously described (Wawrzynska et al., 2005) usually $0.1 \mu \mathrm{g}$ of mRNA, purified with Oligote ${ }^{\circledR}$ mRNA Midi Kit (Qiagen), was used. The real-time reverse-ranscription PCR reactions (real-time RT-PCR) were performed in an iQ5 thermocycler (BioRad, Poland). The pairs of primers used in real-time RT-PCR reactions are listed in Table 1. Each experiment was performed at least twice in triplicates using two independently isolated RNA templates.

Analysis of DNA fragmentation. Genomic DNA was extracted using GenElute ${ }^{\mathrm{TM}}$ Plant Genomic DNA Miniprep Kit (Sigma). DNA was fractionated on $2 \%$ agarose gel and stained with ethid- 
A)
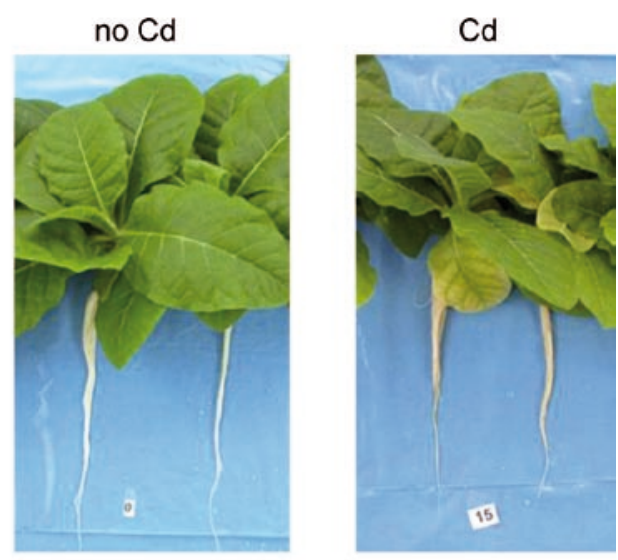

B)

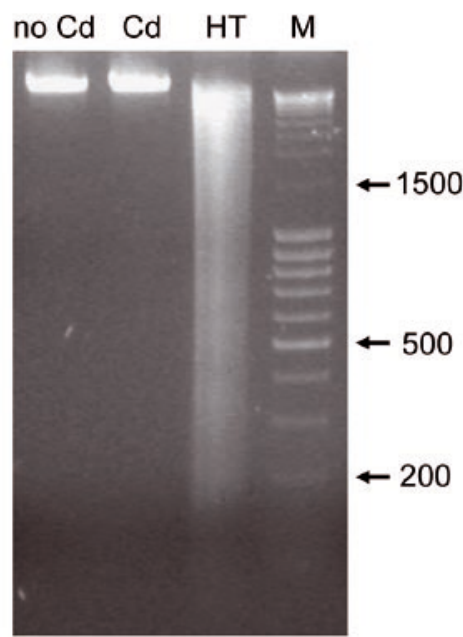

Figure 1. Effects of cadmium on tobacco plants.

A. Symptoms of cadmium toxicity in two-month-old tobacco plants exposed to $15 \mu \mathrm{M} \mathrm{CdCl}_{2}$ for three weeks. B. Lack of DNA fragmentation in tobacco shoots; total genomic DNA was isolated from plants grown in absence (no Cd) and presence (Cd) of $15 \mu \mathrm{M} \mathrm{CdCl}$ for three weeks; genomic DNA from tobacco leaves subjected to heat treatment (see Materials and Methods) was used as a positive control of DNA degradation (HT); molecular marker (M) is shown with positions of selected fragments (size given in base pairs) indicated by arrows.

ium bromide. To obtain a positive control showing symptoms of DNA degradation a modified procedure described previously (Li \& Dickman, 2004) was used. Shortly, leaves of tobacco were incu- bated in $\mathrm{H}_{2} \mathrm{O}$ at $55^{\circ} \mathrm{C}$ for $10 \mathrm{~min}$, next returned to $25^{\circ} \mathrm{C}$ for $24 \mathrm{~h}$ for recovery and used for extraction of genomic DNA.

DNA manipulations and plasmid construction. All restriction enzymes (MBI Fermentas) and T4 DNA ligase (Promega) were used under conditions recommended by the suppliers. Conventional techniques were used for DNA manipulation and transformation (Sambrook et al., 1989).

Sequencing, sequence analysis and accession numbers. Sequencing was carried out by the Laboratory of DNA Sequencing and Oligonucleotide Synthesis, IBB PAS, Warsaw (http://oligo.ibb.waw. $\mathrm{pl} /$ ). Essentially, DNA fragments were automatically sequenced in an ABI3730 DNA Analyzer (Applied Biosystems) using the universal forward or reverse primers homologous to vector sequence. Each sequence was edited to correct sequencing ambiguities and remove the primer sequence. The edited sequences were used to query the GenBank database at NCBI (http://www.ncbi.nlm.nih.gov) using the BLAST sequence comparison algorithms.

The sequences of the tobacco cDNA fragments described in this work were deposited in GenBank (http://www.ncbi.nlm.nih.gov/Genbank) with the accession numbers: EU029649-EU029659. The other sequences used in this study were: X69885 (Tac9), D63396 (EF1a), AF479172 (26S rRNA-encoding gene), D64052 (cTBP).

\section{RESULTS}

\section{Characteristics of plant material}

The above-ground tissues of tobacco plants (Nicotiana tabacum cv. LA Burley 21) grown for three weeks in the absence or presence of $15 \mu \mathrm{M} \mathrm{CdCl}_{2}$ were used as plant material for the experiments described in this study. The basic analysis of the plant material that was performed previously (Wawrzynski et al., 2006) revealed some characteristic differences between $\mathrm{Cd}$-exposed and unexposed plants. Namely, the weight of the shoots from Cd-exposed plants was on average about two times lower than that from plants grown in the control conditions, while the weight of roots was similar. The level of

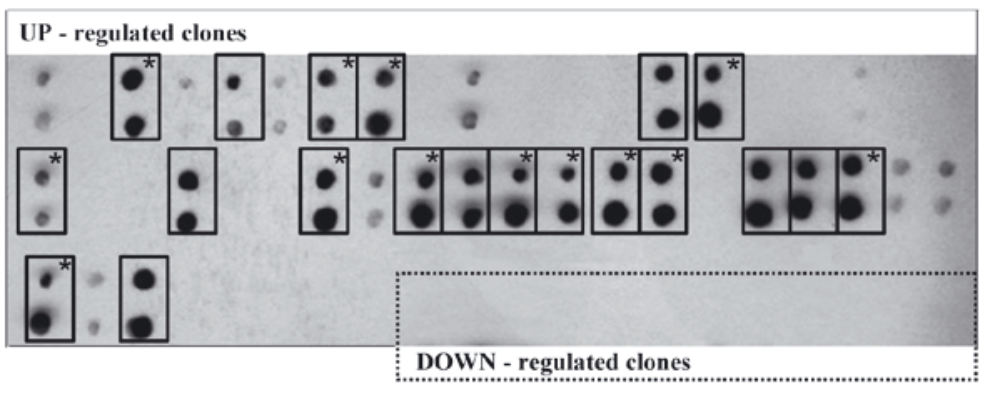

Figure 2. Screening of an SSH library for CD43-like clones.

Clones hybridizing with $\mathrm{CD} 43$ probes are boxed and the sequenced ones are additionally labeled with asterisks. Down-regulated clones were used as a negative control. All clones were spotted in duplicates. 
total thiols in plants exposed to $\mathrm{Cd}$ was about 2.3fold higher in shoots and roots than in the respective parts of un-treated plants. In Cd-exposed plants, accumulation of the toxic metal was about two times higher in roots than in shoots. Although the characteristic symptoms of $\mathrm{Cd}$ toxicity, such as chlorosis of leaves, darkening of roots, and growth inhibition were observed (Fig. 1A), no DNA degradation that is a molecular marker of programmed cell death (PCD) could be detected in shoots of plants exposed to $\mathrm{Cd}$ (Fig. 1B).

\section{Identification of genes regulated by cadmium in tobacco shoots}

Subtractive libraries were prepared from mRNA isolated from shoots. Two sets of the subtracted cDNAs were prepared. The "forward" set provided identification of clones up-regulated by $\mathrm{Cd}$ treatment, while the "reverse" set enabled identification of the down-regulated clones. About 50 plasmids from each set were used separately for initial differential screening for clones representing the regulated genes. About $63 \%$ of clones from the "forward" library and $8 \%$ from the "reverse" library were confirmed to be differentially expressed. The candidate clones were subsequently retested in the second and third rounds of hybridization. Finally, 32 up-regulated and 4 down-regulated clones were chosen for sequencing. Surprisingly, the majority of the up-regulated clones appeared to belong to a large group of overlapping clones that were recognized as $26 \mathrm{~S}$ ribosomal RNA from tobacco (Acc no. AF479172). A representative clone, named $\mathrm{CD} 43$, was used as a probe in an additional round of hybridization to identify other clones of this group (Fig. 2). Among the remaining (non-hybridizing) clones a second group of frequently identified clones, named CD40 family, was also recognized as 26S rRNA. Interestingly, both clones were located in a close neighborhood on $26 \mathrm{~S}$ rRNA but not overlapping each other and they were separated and flanked by sites recognized by the restriction enzyme $R s a I$ (Fig. 3A). Therefore, they resulted most probably from the digestion of cDNA by RsaI that was one of the steps during the preparation of the subtraction libraries.

In summary, the expected regulation was confirmed in the case of $63 \%$ of clones (32 out of 51 analyzed) from the "forward" library. However, about $84 \%$ of these regulated clones (27 clones totally, including 21 from the CD43 family and 6 from the CD40 family) were recognized as 26S rRNA. This result was puzzling since the extracts were supposed to contain exclusively cDNA corresponding to polyadenylated mRNA.

\section{Analysis of CD40 and CD43 families of clones}

Besides the striking similarity to $26 \mathrm{~S}$ rRNA, the CD40 and CD43 clones exhibited a strong similarity to another sequence deposited in data bases, namely to $C T B P$ (Acc no. D64052) that was reported to encode a novel P450-like protein with a monooxygenase activity related to xenobiotic metabolism (Sugiura et al., 1996). Detailed computer analysis of the two tobacco sequences, $26 \mathrm{~S}$ rRNA gene and cTBP CDNA, revealed that they share an extensive region of near-identity at their $5^{\prime}$-ends, while their $3^{\prime}$-ends are different (Fig. 3B). Subsequent $3^{\prime}$-RACE experiments, performed independently for the CD40 and CD43 clones, allowed us to identify multiple polyadenylated 3'-termini located within the analyzed region (Fig. 3B). An analysis of the entire region covered by the sequenced clones showed that the CD40 and CD43 clones were nearly identical $(99.9 \%)$ to the gene for 26S rRNA and strongly similar (97.9\%)

\section{A)}
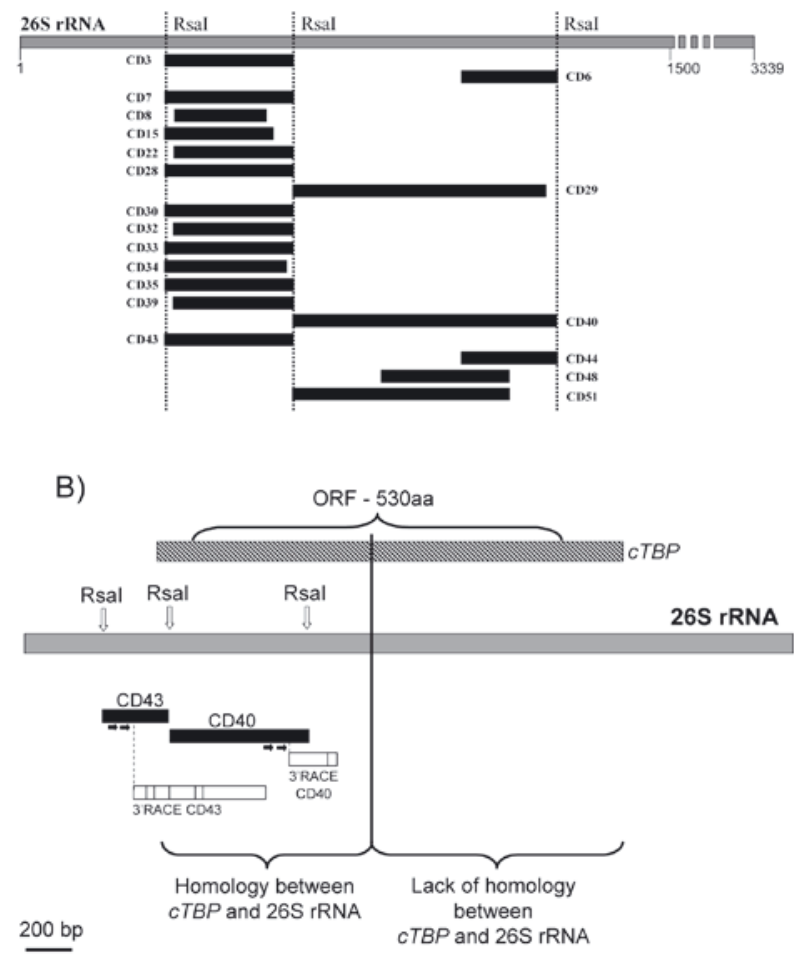

Figure 3. Schematic representation of the CD40 and CD43 families of clones.

Location of CD40 and CD43 families of clones on the molecule of 26S rRNA (A) and a schematic alignment of $26 \mathrm{~S}$ rRNA, cTBP and products of 3'-RACE for CD43 and CD40 (B). The vertical arrows show the positions of the RsaI sites discussed in the text. The small black arrows under the filled black horizontal bars representing CD43 and CD40 show the positions of primers used for 3'-RACE, while the mapped 3 '-ends of mRNA are shown as vertical lines in the respective boxes labeled 3'-RACE CD43 and 3'-RACE CD40, respectively. The scales for panels A and $\mathrm{B}$ are as indicated. 
to $C T B P$ cDNA. This result might suggest that the CD40- and CD43-like clones are rather fragments of degraded and polyadenylated $26 \mathrm{~S}$ rRNA. Additionally, the results of 3 -RACE seem to confirm that the cDNA products corresponding to polyadenylated fragments of $26 \mathrm{~S}$ rRNA were additionally digested by RsaI during the experimental procedure.

To further clarify the problems of homology between cTBP cDNA and the $26 \mathrm{~S}$ rRNA gene, a series of semiquantitative RT-PCR and PCR reactions were performed. The localization of the primers used in these reactions and the results are shown in Fig. 4B. The primers specific for $c T B P$ were designed within two regions: (i) a region with high homology to $26 \mathrm{~S}$ rRNA, namely the forward primer within the region covered by the clone CD40 - RT-CD40F (primer 1) and the reverse primer located downstream of the region covered by the clone CD40 TBPh26SrRNAR (primer 2), and (ii) a region without homology to $26 \mathrm{~S}$ rRNA, namely the forward primer TBPnh26SrRNAF (primer 3) and the reverse primer TBPnh26SrRNAR (primer 4). The sequences of all primers are shown in Table 1. Genomic DNA (for

A)

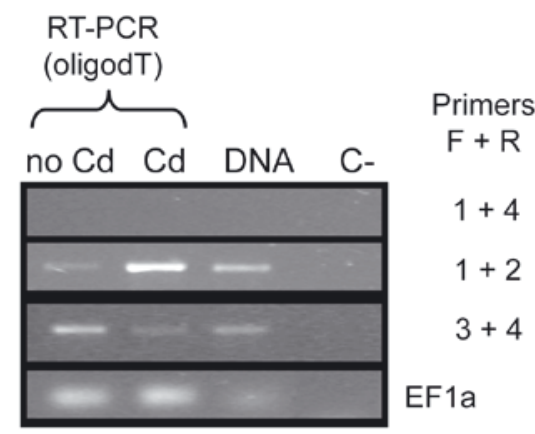

B)

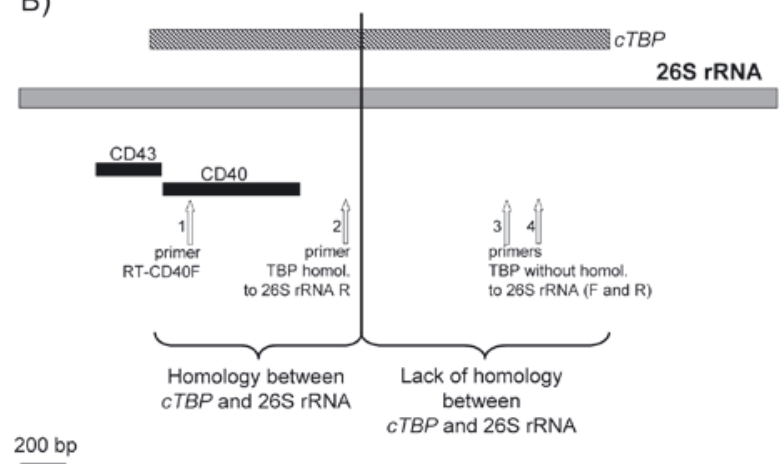

Figure 4. PCR and RT-PCR analysis.

Results (A) and a schematic description (B) of RT-PCR and PCR experiments with primers specific for $c T B P$. mRNA isolated from plants grown with or without $\mathrm{Cd}$ was used a template for RT-PCR while for the PCR reactions total genomic DNA isolated from tobacco grown without $\mathrm{Cd}$ was used; C- indicates a control without template; EF1a indicates the control product with primers EF1a-F and EF1a-R.
PCR reactions) or cDNA (for RT-PCR reactions) prepared from total RNA as a template and oligo(dT) as a primer to reverse transcriptase served as the templates. Total RNA was isolated from both plants grown in the absence and presence of $\mathrm{Cd}$, while genomic DNA was isolated only from plants grown without Cd. PCR products with primers 1 and 4 could not be obtained independently of the template used, while PCR products with the pairs of primers $1+2$ and $3+4$ were obtained with all templates. The increased amount of the $1+2$ product in the case of Cd-treated plants in comparison to the control plants (Fig. 4A) as well as the lack of such regulation in the case of the $3+4$ products seem to be in agreement with the conclusion drawn from the $3^{\prime}$-RACE experiments, namely that the CD40 and CD43 clones originate from $26 \mathrm{~S}$ rRNA rather than from the previously reported $c T B P$ mRNA. The obtained results can be explained by Cd-stimulated degradation and polyadenylation of $26 \mathrm{~S}$ rRNA.

\section{Degradation and polyadenylation of $26 \mathrm{~S}$ rRNA in Cd-treated plants}

Northern-blot analysis was performed in order to verify the phenomenon of polyadenylation of RNA fragments corresponding to 26S rRNA. A commercial mRNA purification kit that utilizes oligo(dT) for specific isolation of polyadenylated mRNAs was used for the extraction of poly(A)-containing RNAs from total RNA isolated from the control and Cdtreated plants. The samples were subsequently used for Northern analysis with the DIG-labeled probe corresponding to a fragment of $26 \mathrm{~S}$ rRNA (CD40). The probe hybridized only to the sample from Cdtreated plants producing an extensive smear indicating degradation of $26 \mathrm{~S}$ rRNA (Fig. 5A). As a quantitative control of the RNA templates a quantitative real-time RT-PCR (real-time RT-PCR) analysis was performed using primers specific to elongation factor $1 \alpha(\mathrm{EF} 1 \mathrm{a})$ and the cDNA obtained from the analyzed mRNA used as the template and oligo(dT) as the primer in the reaction with reverse transcriptase. This method let us confirm the presence of comparable amounts of an EF1a transcript in both samples (Fig. 5B). Furthermore, real-time RT-PCR was used to monitor of the amounts of the polyadenylated RNA fragments corresponding to three different regions of $26 \mathrm{~S}$ rRNA. The location of the amplified fragments on the $26 \mathrm{~S}$ rRNA molecule is shown in Fig. $6 \mathrm{~A}$, while the results of the relevant real-time RT-PCR experiments are presented in Fig. 6B. As expected, considerable amounts of the respective PCR products were obtained only in the case of Cd-treated plants. This result confirms that the cDNA fragments corresponding to $26 \mathrm{~S}$ rRNA were isolated due to the presence of $\operatorname{poly}(\mathrm{A})$ tracks. Either an intact 
A)

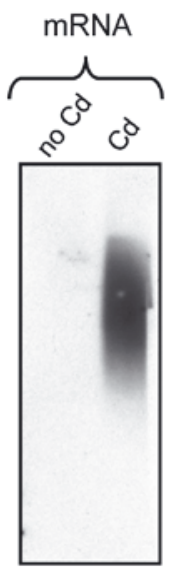

B)

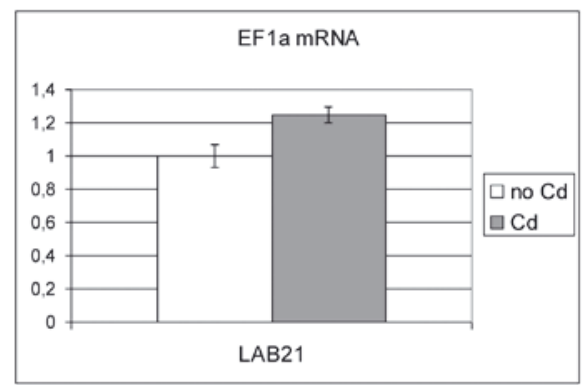

Figure 5. Results of experiments showing the presence of polyadenylated RNA fragments related to 26S rRNA in shoots of tobacco exposed to cadmium.

Northern-blot with a probe covering the CD40 fragment of $26 \mathrm{~S}$ rRNA (A) and real-time RT-PCR of EF1a mRNA as a control.

molecule of $26 \mathrm{~S}$ rRNA or, more probably, fragments that appeared after endoribonucleolytic cleavage of $26 \mathrm{~S}$ rRNA could be used as substrates for such polyadenylation.

\section{DISCUSSION}

In view of the fact that $\mathrm{Cd}$ enters the human and animal body mostly through water and the food chain after being accumulated in plant tissues (Martelli et al., 2006), knowledge of the mechanisms of $\mathrm{Cd}$ accumulation and toxicity in plants is important for an effective protection of human and animal populations from the exposure to this metal.

Although the final reactions of mammalian and plant cells to this toxic metal differ, the effects of $\mathrm{Cd}$ on nucleic acids, proteins, gene expression, induction of oxidative stress are common to both types of cells (Deckert, 2005). In mammals, the proapoptotic effect of $\mathrm{Cd}$ is mediated by various signaling pathways that trigger caspase-dependent and caspase-independent apoptosis (Martelli et al., 2006). Cd-induced cell death has also been observed in plant cells. For example, in tobacco cells a response typical for programmed cell death (PCD), namely
A)

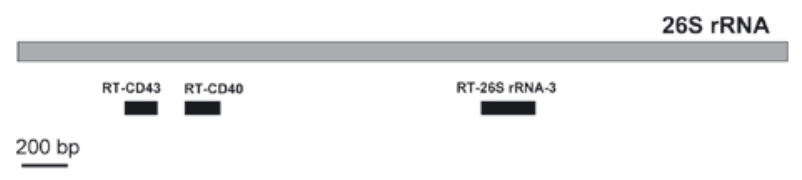

B)

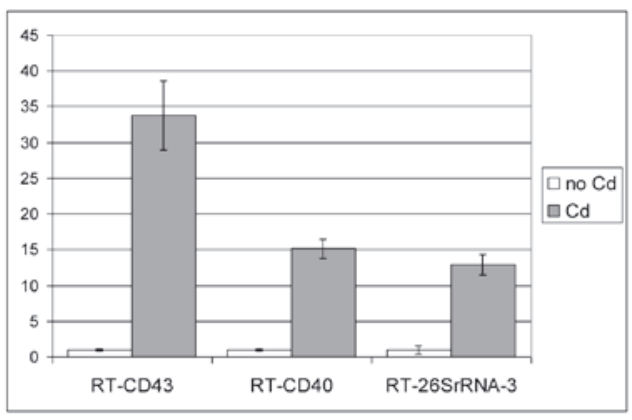

Figure 6. Monitoring of the amount of fragments corresponding to three different regions of 26S rRNA.

Localization of the analyzed RT-PCR fragments on $26 \mathrm{~S}$ rRNA (A) and results of real-time RT-PCR analysis for the indicated fragments (B). For the synthesis of the first cDNA strand, oligo(dT) was used, the specific pairs of primers used for PCR are specified in the text and listed in Table 1.

fragmentation of chromatin into chromatin domains and aberrant morphology of the cells were observed (Fojtova \& Kovarik, 2000). Recent studies on tomato suspension cells suggested that the Cd-induced PCD implied caspase-like proteases, required increased hydrogen peroxide production and activation of ethylene as well as lipid signaling pathways (Yakimova et al., 2006). Specific cleavage of various rRNA species seems to be a typical PCD response known to occur in animals (Houge et al., 1993; 1995; Samali et al., 1997). Moreover, recent studies emphasize the existence of mechanisms to degrade ribosomal RNA in human cells that are possibly coupled to polyadenylation of the intermediates resulting from the endonucleolytic cleavage of rRNAs (Slomovic et al., 2006). Concerning plant cells, only one study has addressed the problem of specific cleavage of ribosomal RNA during PCD induced by a microbial toxin - victorin (Hoat et al., 2006). The authors noticed also a selective degradation of mRNA of housekeeping genes (encoding actin and ubiquitin) and suggested the existence of specific mechanisms of RNA degradation in the apoptotic cells that occur as part of an intrinsic program and can be a new molecular marker of apoptotic cell death in plants (Hoat et al., 2006).

Screening for Cd-responsive genes has been performed for several species, including Arabidopsis thaliana (Suzuki et al., 2001), Brassica juncea (Fusco et 
al., 2005; Minglin et al., 2005), Datura innoxia (Louie et al., 2003), the green alga Chlamydomonas reinhardtii (Rubinelli et al., 2002) and the liverwort Lunularia cruciata (Basile et al., 2005). Differences in both the Cd-treatment conditions and the methods of identification of the Cd-regulated genes might explain why in neither of those studies rRNA-related clones have been found.

To our knowledge, this is the first report about the occurrence of polyadenylation and degradation of ribosomal RNA in plants. The process described in this study occurred in response to acute exposure (21 days) of tobacco plants to low concentration $(15 \mu \mathrm{M})$ of $\mathrm{CdCl}_{2}$, however, taking into consideration the existence of similar processes in mammalian (King et al., 2000; Slomovic et al., 2006) and yeast (Kuai et al., 2004) cells it can be a common phenomenon induced during PCD.

\section{Acknowledgements}

This work was supported by a grant (SPB/ COST/112/2005) from the Ministry of Science and Higher Education.

\section{REFERENCES}

Basile A, Alba di Nuzzo R, Capasso C, Sorbo S, Capasso A, Carginale V (2005) Effect of cadmium on gene expression in the liverwort Lunularia cruciata. Gene 356: 153-159.

Benavides MP, Gallego SM, Tomaro ML (2005) Cadmium toxicity in plants. Braz J Plant Physiol 17: 21-34.

Clemens S, Palmgren MG, Kramer U (2002) A long way ahead: understanding and engineering plant metal accumulation. Trends Plant Sci 7: 309-315.

Clemens S, Schroeder JI, Degenkolb T (2001) Caenorhabditis elegans expresses a functional phytochelatin synthase. Eur J Biochem 268: 3640-3643.

Crawford DR, Lauzon RJ, Wang Y, Mazurkiewicz JE, Schools GP, Davies KJ (1997) $16 \mathrm{~S}$ mitochondrial ribosomal RNA degradation is associated with apoptosis. Free Radic Biol Med 22: 1295-1300.

Deckert J (2005) Cadmium toxicity in plants: is there any analogy to its carcinogenic effect in mammalian cells? Biometals 18: 475-481.

Dreyfus M, Regnier P (2002) The poly(A) tail of mRNAs: bodyguard in eukaryotes, scavenger in bacteria. Cell 111: 611-613.

Fleischmann J, Liu H (2001) Polyadenylation of ribosomal RNA by Candida albicans. Gene 265: 71-76.

Fojtova M, Kovarik A (2000) Genotoxic effect of cadmium is associated with apoptotic changes in tobacco cells. Plant Cell Environ 23: 531-537.

Fusco N, Micheletto L, Dal Corso G, Borgato L, Furini A (2005) Identification of cadmium-regulated genes by cDNA-AFLP in the heavy metal accumulator Brassica juncea L. J Exp Bot 56: 3017-3027.

Herrin DL, Schmidt GW (1988) Rapid, reversible staining of northern blots prior to hybridization. Biotechniques 6: 196-200.
Hoat TX, Nakayashiki H, Tosa Y, Mayama S (2006) Specific cleavage of ribosomal RNA and mRNA during victorin-induced apoptotic cell death in oat. Plant J 46: 922-933.

Houge G, Doskeland SO, Boe R, Lanotte M (1993) Selective cleavage of $28 \mathrm{~S}$ rRNA variable regions V3 and V13 in myeloid leukemia cell apoptosis. FEBS Lett 315: 16-20.

Houge G, Robaye B, Eikhom TS, Golstein J, Mellgren G, Gjertsen BT, Lanotte M, Doskeland SO (1995) Fine mapping of $28 \mathrm{~S}$ rRNA sites specifically cleaved in cells undergoing apoptosis. Mol Cell Biol 15: 2051-2062.

King KL, Jewell CM, Bortner CD, Cidlowski JA (2000) $28 \mathrm{~S}$ ribosome degradation in lymphoid cell apoptosis: evidence for caspase and Bcl-2-dependent and -independent pathways. Cell Death Differ 7: 994-1001.

Kuai L, Fang F, Butler JS, Sherman F (2004) Polyadenylation of rRNA in Saccharomyces cerevisiae. Proc Natl Acad Sci USA 101: 8581-8586.

Lafarga M, Lerga A, Andres MA, Polanco JI, Calle E, Berciano MT (1997) Apoptosis induced by methylazoxymethanol in developing rat cerebellum: organization of the cell nucleus and its relationship to DNA and rRNA degradation. Cell Tissue Res 289: 25-38.

Lam E, Pontier D, del Pozo O (1999) Die and let live programmed cell death in plants. Curr Opin Plant Biol 2: 502-507.

Legg PD, Collins GB, Litton CC (1970) Registration of LA Burley 21 tobacco germplasm. Crop Sci 10: 212.

Li W, Dickman MB (2004) Abiotic stress induces apoptoticlike features in tobacco that is inhibited by expression of human Bcl-2. Biotechnol Lett 26: 87-95.

Louie M, Kondor N, DeWitt JG (2003) Gene expression in cadmium-tolerant Datura innoxia: detection and characterization of cDNAs induced in response to $\mathrm{Cd}^{2+}$. Plant Mol Biol 52: 81-89.

Martelli A, Rousselet E, Dycke C, Bouron A, Moulis JM (2006) Cadmium toxicity in animal cells by interference with essential metals. Biochimie 88: 1807-1814.

Mendoza-Cozatl DG, Moreno-Sanchez R (2006) Control of glutathione and phytochelatin synthesis under cadmium stress. Pathway modeling for plants. J Theor Biol 238: 919-936.

Mendoza-Cozatl D, Loza-Tavera H, Hernandez-Navarro A, Moreno-Sanchez R (2005) Sulfur assimilation and glutathione metabolism under cadmium stress in yeast, protists and plants. FEMS Microbiol Rev 29: 653-671.

Minglin L, Yuxiu Z, Tuanyao C (2005) Identification of genes up-regulated in response to $\mathrm{Cd}$ exposure in Brassica juncea L. Gene 363: 151-158.

Murashige T, Skoog F (1962) A revised medium for rapid growth and bio-assays with tobacco tissue cultures. Physiol Plant 15: 473-493.

Ortega-Villasante C, Rellan-Alvarez R, Del Campo FF, Carpena-Ruiz RO, Hernandez LE (2005) Cellular damage induced by cadmium and mercury in Medicago sativa. J Exp Bot 56: 2239-2251.

Pulido MD, Parrish AR (2003) Metal-induced apoptosis: mechanisms. Mutat Res 533: 227-241.

Rubinelli P, Siripornadulsil S, Gao-Rubinelli F, Sayre RT (2002) Cadmium- and iron-stress-inducible gene expression in the green alga Chlamydomonas reinhardtii: evidence for $\mathrm{H} 43$ protein function in iron assimilation. Planta 215: 1-13.

Samali A, Gilje B, Doskeland SO, Cotter TG, Houge G (1997) The ability to cleave 28S ribosomal RNA during apoptosis is a cell-type dependent trait unrelated to DNA fragmentation. Cell Death Differ 4: 289-293. 
Sambrook J, Fritsch EF, Maniatis T (1989) Molecular Cloning: A Laboratory Manual. Cold Spring Harbor Laboratory Press, Cold Spring Harbor.

Sanita di Toppi L, Gabbrielli R (1999) Response to cadmium in higher plants. Environ Exp Bot 41: 105-130.

Sharma SS, Dietz KJ (2006) The significance of amino acids and amino acid-derived molecules in plant responses and adaptation to heavy metal stress. J Exp Bot 57: 711-726.

Slomovic S, Laufer D, Geiger D, Schuster G (2006) Polyadenylation of ribosomal RNA in human cells. Nucleic Acids Res 34: 2966-2975.

Sugiura M, Sakaki T, Yabusaki Y, Ohkawa H (1996) Cloning and expression in Escherichia coli and Saccharomyces cerevisiae of a novel tobacco cytochrome P-450-like cDNA. Biochim Biophys Acta 1308: 231-240.

Suzuki N, Koizumi N, Sano H (2001) Screening of cadmium-responsive genes in Arabidopsis thaliana. Plant Cell Environ 24: 1177-1188.

Tong YP, Kneer R, Zhu YG (2004) Vacuolar compartmentalization: a second-generation approach to engineering plants for phytoremediation. Trends Plant Sci 9: 7-9. van Doorn WG, Woltering EJ (2005) Many ways to exit? Cell death categories in plants. Trends Plant Sci 10: 117-122.

Wawrzynska A, Lewandowska M, Hawkesford MJ, Sirko A (2005) Using a suppression subtractive librarybased approach to identify tobacco genes regulated in response to short-term sulphur deficit. J Exp Bot 56: 1575-1590.

Wawrzynski A, Kopera E, Wawrzynska A, Kaminska J, Bal W, Sirko A (2006) Effects of simultaneous expression of heterologous genes involved in phytochelatin biosynthesis on thiol content and cadmium accumulation in tobacco plants. J Exp Bot 57: 2173-2182.

Yakimova ET, Kapchina-Toteva VM, Laarhoven LJ, Harren FM, Woltering EJ (2006) Involvement of ethylene and lipid signalling in cadmium-induced programmed cell death in tomato suspension cells. Plant Physiol Biochem 44: 581-589. 